\title{
Spatial separation of copper and cobalt oxalate by flow-driven precipitation
}

\author{
Eszter Tóth-Szeles,${ }^{\dagger}$ Bíborka Bohner, ${ }^{\dagger}$ Ágota Tóth ${ }^{\dagger}{ }^{\dagger}$ and Dezső Horváth*, ${ }^{*}$ \\ Department of Physical Chemistry and Materials Science, University of Szeged, Aradi Vértanúk \\ tere 1., Szeged, H-6720, Hungary, and Department of Applied and Environmental Chemistry, \\ University of Szeged, Rerrich Béla tér 1., Szeged, H-6720, Hungary \\ E-mail: horvathd@chem.u-szeged.hu
}

\section{Abstract}

Precipitation reaction is investigated in a far from equilibrium system by introducing a continuous flow of the homogeneous mixture of water-soluble metal salts into sodium oxalate solution. The spreading gravity current maintained by the density difference between the solutions creates a radially symmetric precipitate pattern that contain spatially separated copper oxalate monohydrate and cobalt oxalate tetrahydrate, indentified by $\mathrm{X}$ ray diffraction measurements. In the transition zone, a unique crystalline composite containing copper oxalate plates with cobalt oxalate coating also forms.

\section{Introduction}

In a homogeneous supersaturated solution nucleation, as a first step of precipitation, can occur in the entire volume. This classical setup initially lacks any spatial gradients that could keep the system away from the thermodynamic equilibrium allowing self-organization to arise. ${ }^{1}$ On the other hand, flow-driven systems represent an entirely different scenario with nucleation taking

\footnotetext{
*To whom correspondence should be addressed

$\dagger$ Department of Physical Chemistry and Materials Science, University of Szeged, Aradi Vértanúk tere 1., Szeged, H-6720, Hungary

†Department of Applied and Environmental Chemistry, University of Szeged, Rerrich Béla tér 1., Szeged, H-6720, Hungary
}

place only at confined zones where the reactants come into contact and mix locally. ${ }^{2,3}$ Gradients of concentration, ${ }^{4} \mathrm{pH},{ }^{5}$ density, ${ }^{6,7}$ and pressure ${ }^{8}$ may drive the precipitation reaction to yield products that are unfavorable in well-stirred reactors.

When a simple precipitation reaction is coupled with flow by injecting a liquid into another one, spatial gradients can be maintained leading to unusual precipitate structures. ${ }^{9-13}$ If the inflowing fluid has greater density, it spreads out at the bottom of the container in the form of a gravity current, which creates a strong convection roll at its tip. Nucleation occurs only in this zone of local mixing; the resulting precipitate pattern will depend on the nature of the reaction and the delicate flow pattern accompanying the gravity current. Behind the tip an unstable stratification develops leading to smaller convection rolls transverse to the direction of radial spreading. Sedimentation is favored on the side of downward flow within these vortices, hence in the copperoxalate system with slow precipitation process radially growing thin lines of precipiate evolves. ${ }^{9,14}$ With practically instantaneous precipitation, the precipitate-lean zones separating the radial lines become less significant or even vanish, and instead an expanding precipitate disk appears as observed in the calcium-oxalate, ${ }^{15,16}$ the calciumcarbonate, ${ }^{17}$ and the cerium-phosphate system. ${ }^{18}$

The non-equilibrium conditions maintained by the gradients have allowed the synthesis of the thermodynamically unstable calcium oxalate dihydrate crystalline form using a simple flow system 
without chemical additives. ${ }^{15}$ Adjusting the flow rate have provided a control over the formation of cobalt oxalate crystals with unique morphology ${ }^{14}$ or over the selective synthesis of calcite in the calcium-carbonate system. ${ }^{17}$

In this work, we are studying the precipitate formation of cobalt and copper oxalate, the morphology control of which is of great interest, since these materials precursors in the fabrication of metal oxide catalysts with different structure. ${ }^{19}$ The similarity in the ionic radii of these transition metal elements can support the formation of solid solutions, like $\mathrm{Co}_{0.7} \mathrm{Cu}_{0.3} \mathrm{C}_{2} \mathrm{O}_{4} \cdot 2 \mathrm{H}_{2} \mathrm{O},{ }^{20}$ which can be distinguished from the mixture of metal oxalates by X-ray diffraction. ${ }^{21}$ The spinel type copper cobaltite catalysts can be prepared by sol-gel synthesis, thermal decomposition of nitrate solutions or different coprecipitation methods like hydroxide, carbonate, or oxalate precipitation. ${ }^{22-25}$ The supported copper cobalt oxide and the $\mathrm{Co}_{2} \mathrm{Cu}$ catalyst prepared by coprecipitation is used for $\mathrm{CO}$ hydrogenation to achieve higher alcohols and ethanol. ${ }^{26-28}$ The spinel-type binary transition metal oxides are utilized as supercapacitors $^{29}$ or electrodes for oxygen evolution reactions. ${ }^{30}$

Transition-metal oxalates are common biominerals found in nature which are typically produced via weathering due to lichen activity. ${ }^{31,32}$ The first reported hydrated copper(II) oxalate mineral, called moolooite with the general formula $\mathrm{CuC}_{2} \mathrm{O}_{4} \cdot \mathrm{nH}_{2} \mathrm{O}$, where $0<n<1$, is formed by the interaction of bird guano and copper sulphide. The copper oxalate built from ribbon-like units consists of $\mathrm{Cu}^{2+}$ and $\mathrm{C}_{2} \mathrm{O}_{4}^{2-}$ ions with octahedral coordination and the water content does not have a great influence on its structure. ${ }^{33}$ In the field of environmental biotechnology, toxic metal compounds can be immobilized by biomineralization, providing metal biorecovery and bioremediation. ${ }^{34}$ The microbial group of fungi is able to create insoluble transition metal oxalate biominerals by excreting oxalic acid. $31,32,35$

Crystallization-based separation processes are widely used in different fields of industry. A mixture of metal salts solution can be separated by fractional crystallization via a chemical reaction based on the different solubility products of the solid components. ${ }^{36}$ This method can be uti- lized in the field of chemical engineering to produce materials with high purity or recover valuable elements from waste solution. ${ }^{37}$ The process is well known in the formation of minerals from the basaltic magma driven by the density differentiation of the crystalline forms. ${ }^{38}$ Furthermore, compositional convection may occur in hydrothermal vents, when a cooling liquid from below containing more than one components leads to unstable density gradients by the crystallization process. ${ }^{39}$

Here we investigate oxalate precipitate formation in a mixture of copper and cobalt salt solution. The introduction of flow allows the development of gradients that leads to the spatial separation of the copper and cobalt oxalate, representing an analogy to fractional crystallization, and provides a control over the crystal morphology. Our experimental study is also augmented with equilibrium calculations to identify the dominant species in the system.

\section{Theoretical section}

In order to calculate the equilibrium composition, we consider the complex formation of oxalate ions in the aqueous phase according to

$$
\begin{array}{ccc}
\mathrm{M}^{2+}+\mathrm{C}_{2} \mathrm{O}_{4}^{2-} & \stackrel{\beta_{O x, 1}}{\rightleftharpoons} & \mathrm{MC}_{2} \mathrm{O}_{4} \\
\mathrm{M}^{2+}+2 \mathrm{C}_{2} \mathrm{O}_{4}^{2-} & \stackrel{\beta_{O x, 2}}{\rightleftharpoons} & \mathrm{M}\left[\mathrm{C}_{2} \mathrm{O}_{4}\right]_{2}^{2-} \\
\mathrm{M}^{2+}+\mathrm{HC}_{2} \mathrm{O}_{4}^{-} & \stackrel{\beta_{H O x, 1}}{\rightleftharpoons} & \mathrm{M}\left(\mathrm{HC}_{2} \mathrm{O}_{4}\right)^{+} \\
\mathrm{Co}^{2+}+2 \mathrm{HC}_{2} \mathrm{O}_{4}^{-} & \stackrel{\beta_{H O x, 2}}{\rightleftharpoons} & \mathrm{Co}\left(\mathrm{HC}_{2} \mathrm{O}_{4}\right)_{2}
\end{array}
$$

in the presence of hydroxo complexes with $1 \leq \mathrm{n}$ $\leq 4$

$$
\begin{array}{ccc}
\mathrm{M}^{2+}+\mathrm{nOH}^{-} & \stackrel{\beta_{n}}{\rightleftharpoons} \mathrm{M}(\mathrm{OH})_{\mathrm{n}}^{2-\mathrm{n}} \\
2 \mathrm{Co}^{2+}+\mathrm{OH}^{-} & \stackrel{\beta_{21}}{\rightleftharpoons} \mathrm{Co}_{2}(\mathrm{OH})^{3+} \\
2 \mathrm{Cu}^{2+}+2 \mathrm{OH}^{-} & \stackrel{\beta_{22}}{\rightleftharpoons} \mathrm{Cu}_{2}(\mathrm{OH})_{2}^{3+}
\end{array}
$$

along with the protonation processes of oxalate ions via

$$
\begin{array}{ccc}
\mathrm{C}_{2} \mathrm{O}_{4}^{2-}+\mathrm{H}^{+} & \stackrel{K_{H, 1}}{\rightleftharpoons} & \mathrm{HC}_{2} \mathrm{O}_{4}^{-} \\
\mathrm{HC}_{2} \mathrm{O}_{4}^{-}+\mathrm{H}^{+} \stackrel{K_{H, 2}}{\rightleftharpoons} & \mathrm{H}_{2} \mathrm{C}_{2} \mathrm{O}_{4}
\end{array}
$$


When the solubility products associated with

$$
\begin{array}{ccc}
\mathrm{MC}_{2} \mathrm{O}_{4}(\mathrm{~s}) & \stackrel{K_{s p, \mathrm{MOx}}}{\rightleftharpoons} \mathrm{M}^{2+}+\mathrm{C}_{2} \mathrm{O}_{4}^{2-} \\
\mathrm{M}(\mathrm{OH})_{2}(\mathrm{~s}) & \stackrel{K_{s p, \mathrm{M}(\mathrm{OH})_{2}}}{\rightleftharpoons} & \mathrm{M}^{2+}+2 \mathrm{OH}^{-}
\end{array}
$$

are reached, the amount of solid precipitate in unit volume is also taken into account in constructing the balance equations.

The equilibrium composition has been calculated by solving the component balance equations for cobalt(II), copper(II) and oxalate ions for various total concentrations. The total concentration of the metal ions is set to $\mathrm{c}_{\mathrm{M}, \mathrm{T}}=0.05-0.4 \mathrm{~mol} / \mathrm{dm}^{3}$ and that of the oxalate to $\mathrm{c}_{\mathrm{Ox}, \mathrm{T}}=0.05 \mathrm{~mol} / \mathrm{dm}^{3}$. Wolfram Mathematica is then used to solve the set of nonlinear equations (see constants in Table 1). The solubility product of the solid copper oxalate is determined by measuring conductivity using the supersaturated solution method.

Table 1: Solubility products and equilibrium constants ${ }^{40,41}$ used in the calculations

\begin{tabular}{ll}
\hline $\mathrm{pK}_{\mathrm{sp}, \mathrm{CoOx}}=8.57$ & $\mathrm{pK}_{\mathrm{sp}, \mathrm{Co}(\mathrm{OH})_{2}}=14.60$ \\
$\log _{10} K_{H, 1}=3.55$ & $\log _{10} K_{H, 2}=1.04$ \\
$\log _{10} \beta_{O x, 1}=3.25$ & $\log _{10} \beta_{O x, 2}=5.60$ \\
$\log _{10} \beta_{H O x, 1}=1.61$ & $\log _{10} \beta_{H O x, 2}=2.89$ \\
$\log _{10} \beta_{1}=3.78$ & $\log _{10} \beta_{2}=8.32$ \\
$\log _{10} \beta_{3}=9.66$ & $\log _{10} \beta_{4}=9.54$ \\
$\log _{10} \beta_{21}=3.10$ & \\
\hline $\mathrm{pK}_{\mathrm{sp}, \mathrm{CuOx}}=8.76$ & $\mathrm{pK}_{\mathrm{sp}, \mathrm{Cu}(\mathrm{OH})_{2}}=18.90$ \\
$\log _{10} \beta_{O x, 1}=4.84$ & $\log _{10} \beta_{O x, 2}=9.21$ \\
$\log _{10} \beta_{H O x, 1}=2.49$ & \\
$\log _{10} \beta_{1}=5.50$ & $\log _{10} \beta_{2}=12.80$ \\
$\log _{10} \beta_{3}=14.50$ & $\log _{10} \beta_{4}=15.60$ \\
$\log _{10} \beta_{22}=16.81$ & \\
\hline
\end{tabular}

\section{Experimental section}

A constant volume of $250 \mathrm{~mL}$ of sodium oxalate (VWR) solution is poured into a glass vessel of $22 \mathrm{~cm} \times 22 \mathrm{~cm} \times 5 \mathrm{~cm}$ size with an inlet hole at the bottom center. Its concentration is varied in the range of $0.05-0.1 \mathrm{~mol} / \mathrm{dm}^{3}$ with $\mathrm{pH}$ set to $6.25 \pm 0.03$ by nitric acid. The homogeneous mixture of copper sulfate and cobalt nitrate (Scharlau) solution with $0.8 \mathrm{~mol} / \mathrm{dm}^{3}$ concentration in $1: 1$ ratio is introduced by a peristaltic pump (Ismatec Reglo) at a constant flow rate of $20 \mathrm{~mL} / \mathrm{h}$ over 8 minutes as seen in Fig. 1. The experiments are carried out at ambient temperature $\left(22 \pm 1{ }^{\circ} \mathrm{C}\right)$.

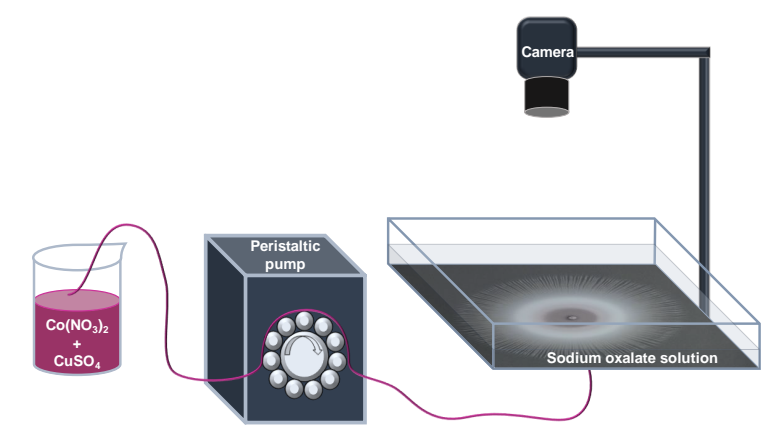

Figure 1: Schematic picture of the experimental setup.

The evolution of the macrostructure is recorded by Unibrain (Fire-i 630c) and Fujifilm Finepix (HS 30 EXR) digital cameras from the top. As the precipitate spreads out, it remains at the bottom of the vessel, hence for the collection of solid samples, the crystals are first washed with distilled water and dried at ambient temperature. The morphology of the crystals is observed by a field emission scanning electron microscope (Hitachi S-4700). The composition of the microstructure is analyzed by energy dispersive spectrometry (Hitachi S-4700 with Röntec X-flash detector) and by a powder Xray diffractometer (Rigaku Ultima IV) with $\mathrm{CuK}_{\alpha}$ radiation and $2 \theta$ scan in the range of $13-55^{\circ}$ with a step size of $1-2 \%$ min. Along the radius of the circular precipitate pattern, the spatial distribution of the cobalt and copper elements is measured at normal atmospheric pressure by fluorescence spectrometry (Horiba Jobin-Yvon XGT-5000 micro XRF) with the incident X-ray generated from a $\mathrm{Rh}$ anode under the conditions of $30 \mathrm{kV}$ and $40 \mathrm{~mA}$ by the X-ray guide tube $10 \mu \mathrm{m}$ in diameter. The cobalt/copper ratio in the precipitate is determined from the recorded the UV-vis spectra of the dioxalato complexes obtained by dissolving $0.1 \mathrm{~g}$ precipitate in $20 \mathrm{~mL}, 0.2 \mathrm{~mol} / \mathrm{dm}^{3}$ sodium oxalate solution. The well-stirred reference experiments are carried out as control systems where $25 \mathrm{~mL}$ of sodium oxalate solution is mixed with $25 \mathrm{~mL}$ solution containing both copper and cobalt ions for $20 \mathrm{~min}$ or $24 \mathrm{~h}$. 


\section{Results and discussion}

The concentration distributions, obtained for various chemical composition, reveal how the amount of metal oxalate precipitates is expected to change as the function of the total oxalate concentration relative to that of the metal ions $(R)$ (see Fig. 2). When metal ions are in high excess $\left(R<10^{-4}\right)$,

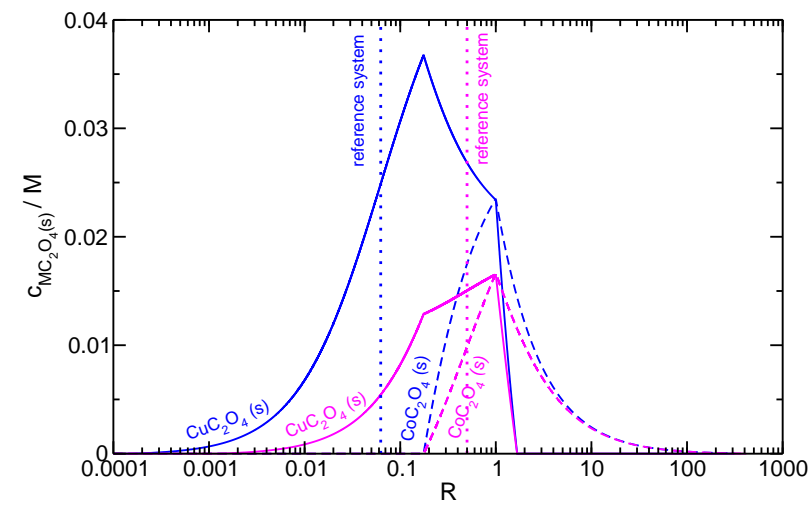

Figure 2: The amount of metal oxalate precipitates in a unit volume as the function of the total oxalate concentration relative to that of the metal ions $(R)$. The solid lines correspond to the copper oxalate precipitate, while the dashed ones to the cobalt (II) oxalate. The blue lines depict the results with $\left[\mathrm{Cu}^{2+}\right]_{\mathrm{T}}=\left[\mathrm{Co}^{2+}\right]_{\mathrm{T}}=0.4 \mathrm{M}$ while the magenta those with $\left[\mathrm{Cu}^{2+}\right]_{\mathrm{T}}=\left[\mathrm{Co}^{2+}\right]_{\mathrm{T}}=0.05 \mathrm{M}$. Dotted lines represent the composition of the precipitates in the reference batch experiments.

there is no significant precipitate formation, as hydrated metal ions are the dominating species. On increasing $R$, copper oxalate precipitate appears first because of its slightly lower solubility product and stronger affinity to form oxalato complexes. The appearance of solid cobalt(II) oxalate only occurs at $R=0.17$, which also breaks the increase in the amount of copper oxalate. The range of coexisting copper and cobalt oxalate precipitates ends by the dissolution of copper oxalate into dioxalato complexes by the further addition of oxalate ion. At greater excess of oxalate ion $\left(R>10^{2}\right)$, the formation of dioxalato complexes are dominant for both metals. The same behavior is observed at lower metal ion concentrations, with less precipitate forming. In Fig. 2, we have also marked the calculated composition for the well-stirred reference experiments with dotted lines, which suggests that when $R=0.0625$ with
$\left[\mathrm{Cu}^{2+}\right]_{\mathrm{T}}=\left[\mathrm{Co}^{2+}\right]_{\mathrm{T}}=0.4 \mathrm{M}$, copper oxalate precipitate forms only, while in case of $R=0.5$ with $\left[\mathrm{Cu}^{2+}\right]_{\mathrm{T}}=\left[\mathrm{Co}^{2+}\right]_{\mathrm{T}}=0.05 \mathrm{M}$, both precipitates coexist.

In the flow-driven system, the homogeneous mixture of cobalt and copper salts is pumped into the less dense stock solution of sodium oxalate, hence the transition metal containing solution spreads out horizontally at the bottom of the vessel leading to the formation of a gravity flow. The leading edge of the gravity current is hydrodynamically unstable creating a mixing zone where the precipitates form. Furthermore, the gravity current drives the sedimentation of the solid particles along the side of downward flow within the convection rolls perpendicularly to the spreading. The formation of the macroscopically distinct filamental precipitate pattern is defined as a footprint of the gravity current similar to the pure copper oxalate $^{9}$ or cobalt oxalate ${ }^{14}$ systems. The precipitate pattern consists of an inner circle with less precipitate sedimentation in the vicinity of the inlet, which is surrounded by a pinkish then a blue precipitate zone. Moving outward, the radial lines change colors from blue to pale pink as seen in Fig. 3 (a). The light blue parts correspond to the copper oxalate precipitate and the pale pink regions are identified as the solid cobalt oxalate. Thus, in spite of the small difference in the solubility products of copper and cobalt oxalate, significant spatial separation can be achieved using this flow-driven synthesis.

The microstructure of the dry precipitate is investigated at two different oxalate concentrations by scanning electron microscopy and the composition of the characteristic crystalline forms is analyzed by energy dispersive spectrometry. The inner bluish part consists of spherical copper(II) oxalate particles with diameter of $\sim 5 \mu \mathrm{m}$ mixed with cobalt oxalate $5 \mu \mathrm{m}$ long needle-like crystals as depicted in Fig. 3 (b). Toward the tip of the filaments, the shape of the particles changes in accordance with the color transition. By moving farther from the inner blue area, cobalt(II) oxalate prismatic crystals with diameter of $20-25 \mu \mathrm{m}$ dominate as seen in Fig. 3 (c-d), building up the bright pink filamental structure. In the presence of copper ions, the resultant rod-like and prismatic aggregates of the cobalt oxalate crystals are different from the 
spherulite morphology of the pure cobalt oxalate precipitate synthesized in a flow-driven system. ${ }^{14}$

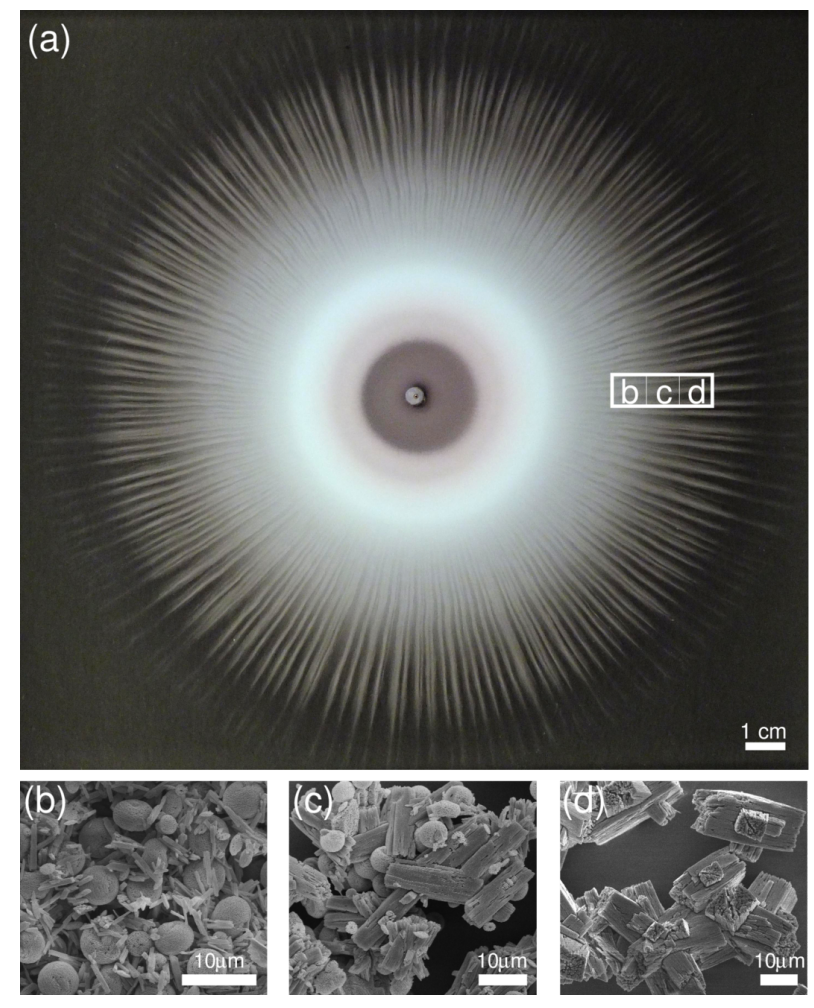

Figure 3: The filamental structure of the copper-cobalt-oxalate precipitate pattern (a) and the SEM images of the microstructure from the corresponding zone $(\mathrm{b}-\mathrm{d})$. Experimental conditions: $\left[\mathrm{M}^{2+}\right]=0.8 \mathrm{~mol} / \mathrm{dm}^{3}$, $\left[\mathrm{Na}_{2} \mathrm{C}_{2} \mathrm{O}_{4}\right]=0.1 \mathrm{~mol} / \mathrm{dm}^{3}$ and $\mathrm{w}=20 \mathrm{ml} / \mathrm{h}$, $\mathrm{t}=480 \mathrm{~s}$.

Comparison of the size and the morphology in the flow-induced and the well-stirred batch experiments demonstrates that the presence of spatial gradients leads to the formation of larger particles. The simultaneous addition of the sodium oxalate solution $\left(\left[\mathrm{Na}_{2} \mathrm{C}_{2} \mathrm{O}_{4}\right]=0.1 \mathrm{~mol} / \mathrm{dm}^{3}\right)$ to the copper sulfate solution $\left(\left[\mathrm{Cu}^{2+}\right]=0.8 \mathrm{~mol} / \mathrm{dm}^{3}\right)$ yields copper oxalate precipitate in a few seconds with hollow ellipsoid morphology and diameter 1$2 \mu \mathrm{m}$. When oxalate concentration is decreased to $0.05 \mathrm{~mol} / \mathrm{dm}^{3}$, cushion-like particles are the products with uniform distribution. The reference batch synthesis for the mixed copper-cobaltoxalate system using 1:1 metal ion:oxalate ion molar ratio reveals the formation of smaller solid particles in contrast to the flow synthesis, resulting in a mixture of spherical copper oxalate and prismatic cobalt oxalate particles as seen in Fig. 4 (a).
By using eightfold metal ion excess in the one-pot experiments with concentrations identical to the flow synthesis, we can produce pure copper oxalate precipitate with platelles morphology (Fig. 4 (b)). This is in good agreement to the prediction of equilibrium calculation.
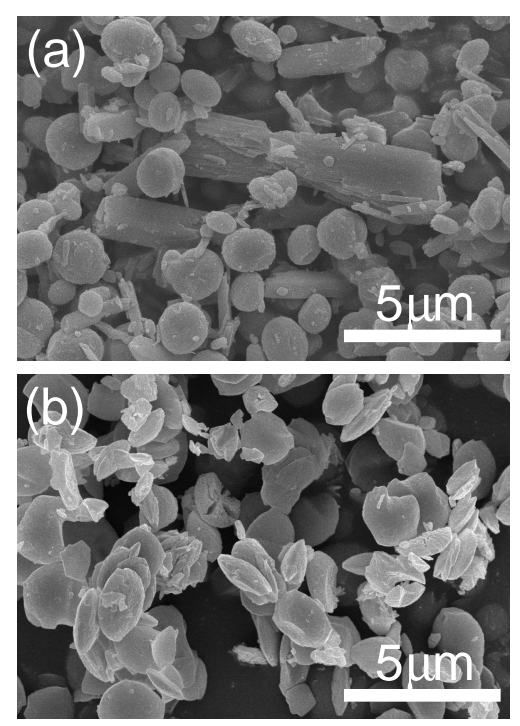

Figure 4: SEM images of the precipitates in the well-stirred reference systems of $\left[\mathrm{Na}_{2} \mathrm{C}_{2} \mathrm{O}_{4}\right]=0.1 \mathrm{~mol} / \mathrm{dm}^{3}$ and $\left[\mathrm{M}^{2+}\right]=0.1 \mathrm{~mol} / \mathrm{dm}^{3}$ resulting in a mixture of copper and cobalt oxalate (a) and of $\left[\mathrm{M}^{2+}\right]=0.8 \mathrm{~mol} / \mathrm{dm}^{3}$ leading to pure copper oxalate (b). In both cases $t=20 \mathrm{~min}$ and $r=400$ rpm.

To determine the composition of the solid particles in the mixture, we have also analyzed the samples by X-ray diffractometry. The less stable cobalt(II) oxalate tetrahydrate (orange diffractogram in Fig. 5) forms first, in accordance with our previous work, ${ }^{14}$ which later transforms into dihydrate (red curve). A reference pure copper oxalate precipitate (light blue curve) is also synthesized by the flow-driven method under the conditions identical to those in Fig. 3. The diffraction pattern of the bluish part proves that the sample contains the mixture of the copper oxalate monohydrate and cobalt oxalate dihydrate as seen in Fig. 5.

By decreasing the concentration of the sodium oxalate, the density difference between the solutions increases and the gravity current strengthens which leads to the disappearance of the precipitate ring around the precipitate-free inner region. 


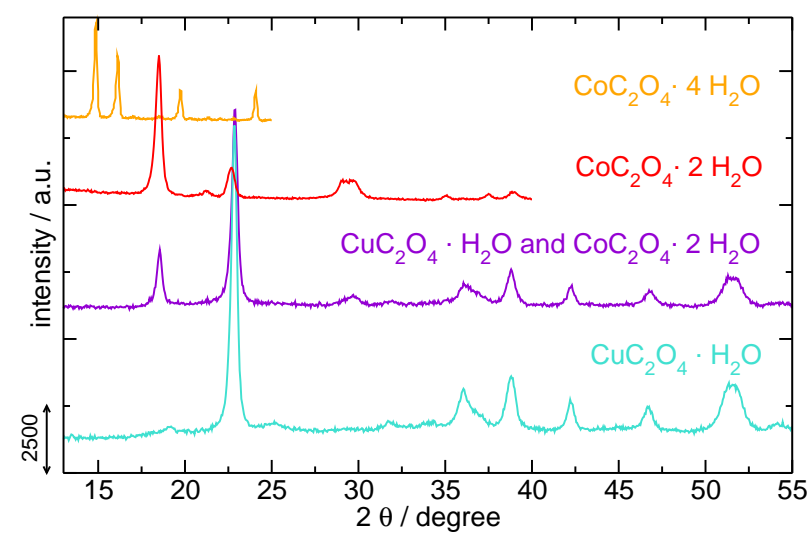

Figure 5: The powder diffraction pattern of the greyish pink cobalt oxalate tetrahydrate (JCPDS No. 00-037-0534) (orange line), the bright pink cobalt oxalate dihydrate (JCPDS No. 00-0481068) (red line), and the sample from the blue ring of the precipitate in Fig. 3 (purple line). The experimental conditions are identical to those of Fig. 3. Also shown is the pure copper(II) oxalate synthesized similarly (JCPDS No. 210-297) (cyan line).

The filamental structure hence becomes more distinct as depicted in Fig. 6. The X-ray fluorescence analysis reveals the radial distribution of the copper and cobalt elements. At the edge of the transparent circle, the copper rich area contains $85 \%$ copper atoms (see Fig. 7 (a)). The copper to cobalt ratio becomes 1 , creating a transition zone $58 \mathrm{~mm}$ far from the inlet. At the tip of the filaments, $96 \%$ cobalt content is achieved due the depletion of the copper ions at the bottom as the precipitate pattern develops.

The microstructure of the solid particles comprising the filaments is characterized with various crystalline forms along the radius from the rim of the precipitate free area to the tip of the precipitate filaments. The inner copper rich zone exhibits spherical copper oxalate particles with needleshaped cobalt oxalate as observed at greater oxalate concentration, see in Fig. 7 (b). In the transition zone, there are $5 \mu \mathrm{m}$ long crystals that comprise copper oxalate plates with cobalt oxalate coatings as illustrated in Fig. 7 (c). At the tip of the filaments rod-like cobalt oxalate crystals dominate with the length of $10 \mu \mathrm{m}$.

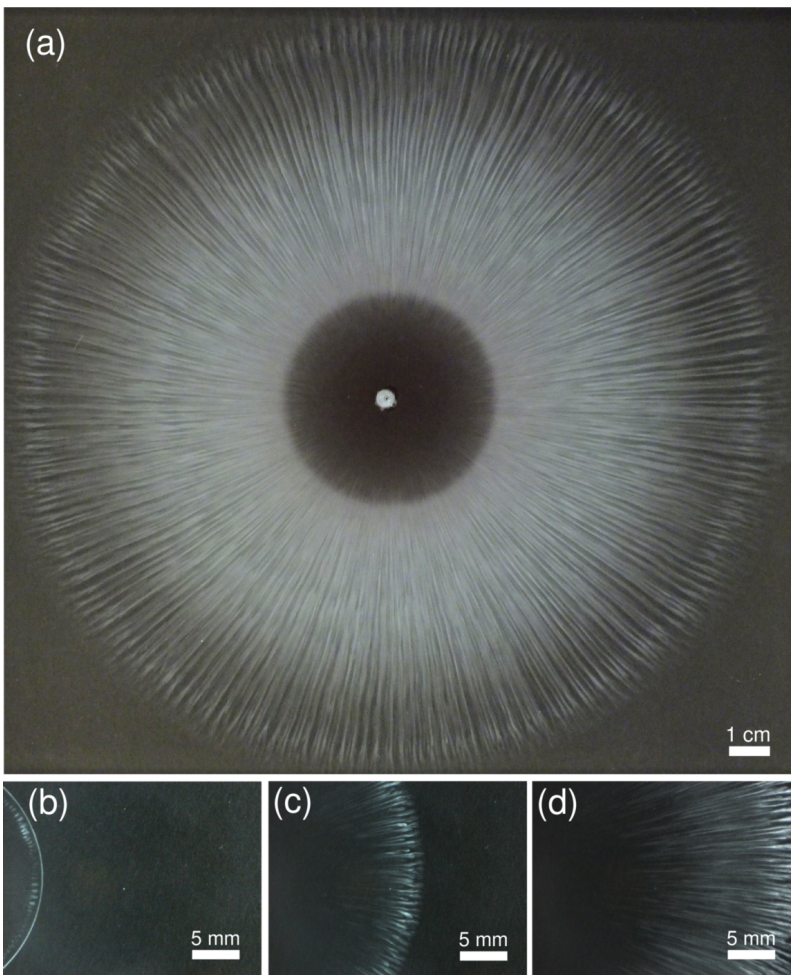

Figure 6: The photo of the bluish filamental structure developed in the flow-driven coppercobalt-oxalate system at $t=420 \mathrm{~s}$ (a). Enlargement of the precipitate propagation with the temporal evolution of the filaments at $t=15 \mathrm{~s}$ (b), $t=45 \mathrm{~s}$ (c), and $t=90 \mathrm{~s}$ (d). Experimental conditions: $\left[\mathrm{M}^{2+}\right]=0.8 \mathrm{~mol} / \mathrm{dm}^{3}$, $\left[\mathrm{Na}_{2} \mathrm{C}_{2} \mathrm{O}_{4}\right]=0.05 \mathrm{~mol} / \mathrm{dm}^{3}$ and $w=20 \mathrm{ml} / \mathrm{h}$. 


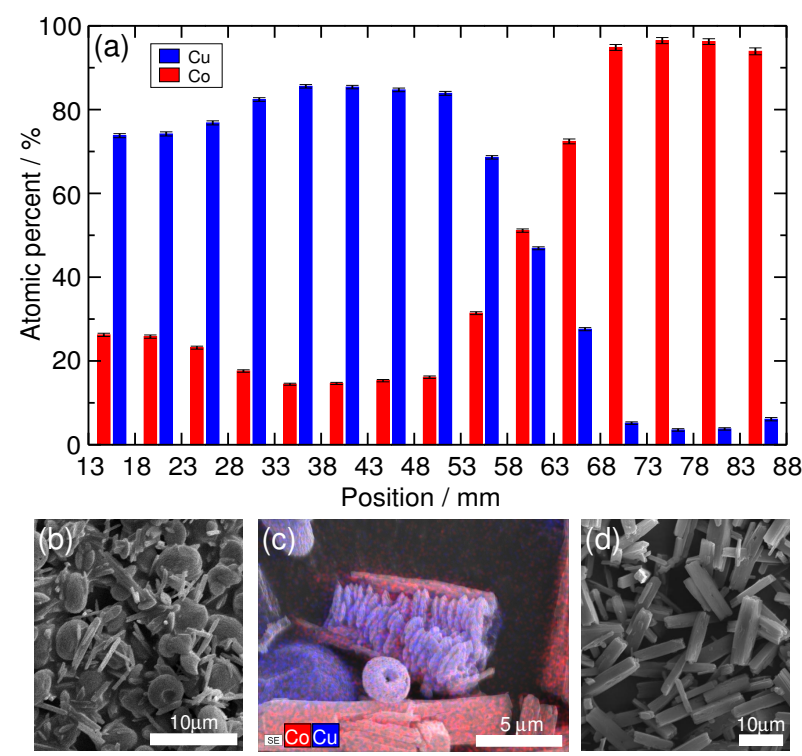

Figure 7: The spatial distribution of the cobalt and copper in $15 \times 5 \mathrm{~mm} \times 5 \mathrm{~mm}$ scanning area started $13 \mathrm{~mm}$ far from the inlet (a). SEM image of the precipitate in the range of $13-53 \mathrm{~mm}$ far from the inlet (b), in the transition zone up to $68 \mathrm{~mm}$ (c), and at the tip of the filaments (d). The experimental conditions are identical to those of Fig. 6.

\section{Conclusion}

Precipitate pattern formation in the copper-cobaltoxalate system is investigated far from equilibrium by introducing the continuous flow of the homogeneous mixture of the water-soluble metal salts. Upon contact with sodium oxalate solution, the precipitation process is not instantaneous leaving a clear liquid free of solid particles around the inlet. The spreading solution at the bottom in the form of a gravity current then results in radially growing lines along which precipitate sedimentation occurs. Along these lines, the spatial separation of copper oxalate monohydrate and cobalt oxalate tetrahydrate takes place, as supported by Xray diffractometry. The microstructure of the solid particles is characterized with rod-like and prismatic aggregates instead of the spherulite shape associated with pure cobalt oxalate. Furthermore, in the thin transition region, unique crystals containing copper oxalate plates with cobalt oxalate coatings are observed. These experiments demonstrate that the presence of spatial gradients, maintained by the flow in this particular example, can be utilized in a controlled manner in synthesizing precipitates with morphology different from those obtained in well-stirred batch systems.

\section{Acknowledgments}

This work has been supported by the National Research, Development and Innovation Office (K119795) and ESA (ESTEC 4000102255/11/NL/KML).

\section{References}

(1) Nakouzi, E.; Steinbock, O. Sci. Adv. 2016, 2, e1601144.

(2) Cartwright, J. H. E.; García-Ruiz, J. M.; Novella, M. L.; Otálora, F. J. Coll. and Interface Sci. 2002, 256, 351-359.

(3) Thouvenel-Romans, S.; Steinbock, O. J. Am. Chem. Soc. 2003, 125, 4338-4341.

(4) Batista, B. C.; Cruz, P.; Steinbock, O. Langmuir 2014, 30, 9123-9129.

(5) Zhang, G.; Delgado-López, J. M.; ChoquesilloLazarte, D.; Garía-Ruiz, J. M. Cryst. Growth Des. 2015, 15, 564-572.

(6) Devon, R.; RoseFigura, J.; Douthat, D.; Kudenov, J.; Maselko, J. Chem. Commun. 2005, 13, 1678-1680.

(7) Kaminker, V.; Maselko, J.; Pantaleone, J. J. Chem. Phys. 2014, 140, 244901.

(8) Mirsaleh-Kohan, N.; Fischer, A.; Graves, B.; Bolorizadeh, M.; Kondepudi, D.; Compton, R. N. Cryst. Growth Des. 2017, 17, 576-581.

(9) Baker, A.; Tóth, A.; Horváth, D.; Walkush, J.; Ali, A.; Morgan, W.; Kukovecz, A.; Pantaleone, J.; Maselko, J. J. Phys. Chem. A 2009, 113, 8243-8248.

(10) Makki, R.; Roszol, L.; Pagano, J. J.; Steinbock, O. Phil. Trans. R. Soc. A 2012, 370, 2848-2865.

(11) Maselko, J.; Kiehl, M.; Couture, J.; Dyonizy, A.; Kaminker, V.; Nowak, P.; Pantaleone, J. Langmuir 2014, 30, 5726-5731.

(12) Cardoso, S. S.; Cartwright, J. H.; Checa, A. G.; SainzDíaz, C. I. Acta Biomater. 2016, 43, 3338-347.

(13) Schuszter, G.; Brau, F.; De Wit, A. Environ. Sci. Technol. Lett. 2016, 3, 156-159.

(14) Tóth-Szeles, E.; Schuszter, G.; Tóth, Á.; Kónya, Z.; Horváth, D. CrystEngComm 2016, 18, 2057-2064. 
(15) Bohner, B.; Schuszter, G.; Berkesi, O.; Horváth, D.; Tóth, Á. Chem. Commun. 2014, 50, 4289-4291.

(16) Bohner, B.; Endrôdi, B.; Horváth, D.; Tóth, Á. J. Chem. Phys. 2016, 144, 164504.

(17) Bohner, B.; Schuszter, G.; Horváth, D.; Tóth, Á. Chem. Phys. Lett. 2015, 631, 114-117.

(18) Pusztai, P.; Tóth-Szeles, E.; Horváth, D.; Tóth, Á.; Kukovecz, Á.; Kónya, Z. CrystEngComm 2015, 17, 8477-8485.

(19) Bowen, P.; Pujol, O.; Jongen, N.; Lemaître, J.; Fink, A.; Stadleman, P.; Hofmann, H. Nanoscale 2010, 2, 2470-2477.

(20) Donia, A. M.; Dollimore, D. Thermochim. Acta 1997, 290, 139-147.

(21) Schuele, W. J. J. Phys. Chem. 1959, 63, 83-86.

(22) Singh, R.; Pandey, J.; Singh, N.; Lal, B.; Chartier, P.; Koenig, J.-F. Electrochim. Acta 2000, 45, 1911-1919.

(23) Tavares, A.; Cartaxo, M.; da Silva Pereira, M.; Costa, F. J. Electroanal. Chem. 1999, 464, 187-197.

(24) ICAL, E. Int. J. Electrochem. Sc. 2007, 2, 762-777.

(25) Donia, A.; Radwan, N.; Atia, A. J. Therm. Anal. Calorim. 2000, 61, 249-261.

(26) Cao, R.; Pan, W.; Griffin, G. L. Langmuir 1988, 4, 1108-1112.

(27) Xiang, Y.; Barbosa, R.; Kruse, N. ACS Catal. 2014, 4, 2792-2800.

(28) Prieto, G.; Beijer, S.; Smith, M. L.; He, M.; Au, Y.; Wang, Z.; Bruce, D. A.; De Jong, K. P.; Spivey, J. J.; De Jongh, P. E. Angew. Chem. Int. Edit 2014, 53, 63976401.

(29) Pendashteh, A.; Moosavifard, S. E.; Rahmanifar, M. S.; Wang, Y.; El-Kady, M. F.; Kaner, R. B.; Mousavi, M. F. Chem. Mater. 2015, 27, 3919-3926.

(30) La Rosa-Toro, A.; Berenguer, R.; Quijada, C.; Montilla, F.; Morallón, E.; Vázquez, J. J. Phys. Chem. B 2006, 110, 24021-24029.

(31) Gadd, G. M. Mycol. Res. 2007, 111, 3-49.

(32) Fomina, M.; Hillier, S.; Charnock, J.; Melville, K.; Alexander, I.; Gadd, G. Appl. Environ. Microb. 2005, $71,371-381$.

(33) Clarke, R.; Williams, I. Mineral. Mag. 1986, 50, 295298.

(34) Gadd, G. Environmental and Microbial Relationships; Springer, 2016; pp 99-125.
(35) Kaewdoung, B.; Sutjaritvorakul, T.; Gadd, G. M.; Whalley, A. J.; Sihanonth, P. Geomicrobiol. J. 2016, 33, 283-288.

(36) Cisternas, L. A.; Vásquez, C. M.; Swaney, R. E. AIChE J. 2006, 52, 1754-1769.

(37) Parthasarathy, G.; Dunn, R. F. Adv. Environ. Res. 2004, $8,247-265$.

(38) Sparks, R. S. J.; Huppert, H. E. Contrib. Mineral. Petr. 1984, 85, 300-309.

(39) Tait, S.; Jahrling, K.; Jaupart, C. Nature 1992, 359, 406-408.

(40) Kotrlý, S.; Šůcha, L. Handbook of Chemical Equilibria in Analytical Chemistry; Ellis Horwood Ltd, 1985.

(41) Soare, L. C. Precipitation and transformation of nanostructured copper oxalate and copper/cobalt composite precursor synthesis. Ph.D. thesis, EPFL, 2004. 